\title{
DISSERTAÇÃO
}

\section{POSIÇÃO JURIDICA DOS ESTADOS FEDERADOS}

\author{
PERANTE O \\ ESTADO FEDERAL
}

A necessidade de precisar certas idéas, sobre as quaes vemos reinar a mais lamentavel confusão, a respeito da natureza do Estado Federal, suggeriu-nos a escolha deste assumpto para o objecto de nossa dissertação de concurso.

Com effeito, estabelecido, não ha muito, o noro regimen pelo qual se modelou a organisação politica brasileira, nota-se, em geral, entre politicos, e mesmo entre muitos juristas, completa carencia de conhecimentos sobre algumas noções que, pelo seu caracter de novidade, ainda não tem constituido objecto de dedicado estudo por parte dos competentes.

Dahi, uma timidez manifesta, e um vacillar constante na enunciação de conceitos attinentes ás difficuldades que se levantam no campo do direito federal. 
Eis porque, parecendo.nos opportuno qualquer trabalho, por mais modesto que seja, sobre este ramo das materias componentes do curso juridico, resolvemos traçar algumas linhas com o fim de determinar a posição exacta dos Estados federados em frente do Estado federal.

A primeira questão que surge neste estudo, e que constitue, pode-se dizer, a base de toda a theoria sobre o Estado federal, é a de saber-se onde assenta a soberania, isto é, si ella existe só nos Estados particulares que o compõem, si dupla, ou dual, como dizem outros, encontra-se não só nesses Estados como tambem na União federal, ou si reside exclusivamente nesta como entidade complexa formando um verdadeiro Estado.

$\mathrm{O}$ interesse com que se tem discutido este ponto, é justificado não só pela sủa importancia prática, porque é da determinação precisa da soberania que decorrem os direitos e deveres dos Estados e da União, como ainda porque, de lados oppostos, hão disputado com ardor pensadores da estatura de Jefferson, Calhoun, Tocqueville e Zorn. E foi mesmo em virtude dos sentimentos produzidos pela propaganda exaggerada do fundador da States Rights Schoo!, em prol da soberania dos Estados particulares, que rebentou na America do Norte a celebre guerra de secessão, a mais sanguinolenta e a mais ruinosa dos tempos modernos, na phrase de Summer Maine. (1)

Das tres theorias expostas e sustentadas por esses eminentes escriptores, a primeira affirmando que a soberania, por ser necessariamente indivisivel, só existe nos Estados federados, e de modo algum no Estado federal, a segunda estabelecendo que é nepag. 351 .

(1) Summer Maine - Ess. sur le Gounvern. Popul. (Trad. franc. 
cessaria a partilha da soberania, e que, portanto, não só este é soberano, como tambem o é cada um dos Estados membros, e a terceira asseverando que só a União federal possue a soberania que é, por sua natureza indivisivel, impartilhavel, parece-nos que só esta ultima se alicerceia em solidos fundamentos juridicos, sendo que, por isso, vai conquistando os espiritos cultos, sinão na America, pelo menos na Europa, e particularmente na Allemanha.

Entre nós, ainda se torna perigoso, ás vezes, enunciar uma verdade destas, perante alguns politicos que, imbuidos das eloquentes lições de Tocqueville, se aprazem em terçar pela famosa "soberania dos Estados»

Para demonstrar a procedencia da ultima theoria referida, evidenciando, a mesmo tempo, a inteira falsidade das duas primeiras, em face dos principios do direito, bem como perante as constituições federaes mais importantes, mister se faz, antes de tudo, que demos aqui uma noção juridica exacta do que seja soberania.

1 Deixando de parte as velhas indagações sobre as fontes da soberania, conforme as procuravam os sectarios das quatro escolas principaes que se disputavam a verdade, a escola theocratica, a legitimista, a liberal e a radical, trataremos apenas de indicar precisamente a sua natureza, tal como é estabelecida pelo direito.

Para Bodin, foi a soberania considerada como o summum imperium, a suprema potestas, isto é, o poder supremo e perpetuo da Republica.

Mas essa definição, envolvendo uma idéa por demais absoluta, não se compadece com os principios 
da sciencia, por isso que, comn diz Bluntschli, (2) «o Estado representativo moderno não conhece semelhante poder, e a independencia absoluta não é deste mundo. O proprio Estado, em seu conjuncto, não é omnipotente: os direitos dos'outros Estados o restrigem no exterior, os de seus membros e dos individuos no interior».

Para acceitar-se como verdadeira a noção de Bodin, seria preciso limitar-se aquelle suprêmo poder, porque, si, de facto, o Estado, como a mais perfeita organisação politica de um povo, possue sobre seu territorio um poder superior, não sendo possivel assistir acima delle qualquer outro poder humano, todavia, não lhe é dado agir de modo arbitrario, creando direitos e deveres, segundo as exigencias de sua vontade; não: na organisação dos poderes publicos, como no estabelecimento das leis indispensaveis á garantia dos cidadãos, elle precisa attender ás necessidades geraes, cuja satisfação se impõe como condição imprescindivel á coexistencia dos individuos e ao desenvolvimento da sociedade, tem de obedecer ás circumstancias produzidas pelos effeitos das leis biologicas e sociaes, em uma palavra, deve exercer a sua activiuade dentro dos limites intransponiveis traçados pelos principios do direito.

Assim entendida, a soberania pode ser considerada como o mais elevado poder do Estado, como a fonte de que decorrem todos os seus direitos sobre os individuos e as collectividades inferiores que se acham no mesmo territorio.

() Bluntschli - Th. de L' État. (Trad. franc.) 2." ed. pag. 435

Lastarria - Politique Positive. (Trad. franc.) pag. 285: "A soberania nacional, sendo un direito, não pode em principio, desviar-se da justiça ou das condições que constituem a vida, o progresso e os elementos da sociedade." 
Do mesmo modo que a capacidade juridica do individuo comprehende todos os seus direitos, assim a soberania, affirmação da capacidade juridica do Estado, comprehende todos os direitos publicos, ou, syntheticamente, ella é o proprio direito do Estado na sua mais elevada expressão. ${ }^{(3)}$

O distincto escriptor moderno Le Fur, em sua excellente obra ultimamente publicada, $\left({ }^{4}\right)$ diz, de maneira explicativa e clara, que "a soberania é a qualidade em virtude da qual a fórma da organisação humana a mais elevada, o Estado, possue absolutamente a independencia em frente de qualquer outro poder humano, e, relativamente, em toda a extensão de um territorio determinado, o direito de mandar sobre toda pessôa physica ou moral que se ache neste territorio, donde resulta, para elle, o direito de fixar livremente sua propria ccmpetencia em relação a essas pessôas, dentro dos limites do principio superior do direito.»

E', pois, na determinação livre de sua competencia, que se encontra o criterio pelo qual se pode ver a manifestação da soberania sobre um territorio dado. O Estado que definitivamente não tiver a "competencia da competencia", (Kompetenz Kompetenz) segundo a breve expressão dos auctores allemães, não pode possuir a soberania, ou, mais correctamente, percle () caracteristico essencial de um verdadeiro Estado. $\left(^{\check{5}}\right)$

Firmada essa noção, de modo a podermos bem entendel-a, sem arriscados exaggeros, comprehende-se

(3) Orlando-Princ. di Dir. Costituzionale.

${ }^{(4)}$ Le Fur - État Fédérale et Conf. d' État.

(5) Os membios componentes de um Estado federal, que recebem o noıne de Estados, na maioria das constituições, não merecem esse nome perante a sciencia juridica. Falta-lhes o requisito essencial do Estado: a soberania. 
que, por isso mesmo que é indispensavel ao Estado soberano, uma completa independencia de qualquer outro poder humano, segue-se que é manifesta a indivisibilidade da soberania, pois, em um só territorio, que é um dos elementos constitutivos do Estado, é de todo impossivel a coexistencia de dois poderes soberanos.

Com effeito, fragmentada a soberania pelos diversos individuos ou collectividades inferiores do Estado, a consequencia fôra que cada uma dessas entidades possuiria apenas uma parte della, e, então, nenhuma constituiria de per si um poder soberano; mas, neste caso, a falta de uma auctoridade suprêma, garantidora das relações juridicas entre esses diversos membros, produziria a desordem na sociedade, e, em virtude da impossibilidade de qualquer fórma de governo, o anarchismo surgiria como um acontecimento fatal.

Demais, a partilha da soberania é inconciliavel com a unidade necessaria á personalidade juridica do Estado.

O fraccionamento daquella, arrastaria, ipso facto, a destruição deste.

-Imperium, nisı unum sit, esse nullun potest, - dizia Cicero. $\left({ }^{6}\right)$

"A unidade é condição necessaria de todo bom organismo, escreve Bluntschli. A divisão da soberania paralysa e dissolve: ella é incompativel com a saúde do Estado." ( $\left.{ }^{7}\right)$

Convém notar, porém, que, si a indivisibilidade é requisito essencial á soberania, comtudo, não é contrario á sua natureza que ella possa soffrer algumas restriç̧ões especiaes. Assim como os individuos po-

(') Cicero. - De Rep. L. 1 C. 8

(?) Bluntschli. - Op. cit. pag. 436 . 
dem, por meio de certos contractos, estabelecer limites, fazer restricções ao exercicio de seus direitos, sem por isso perderem a sua capacidade juridica, uma vez que taes contractos presupponham a livre manifestação da vontade, por parte daquelle que se obriga, do mesmo modo o Estado, que é por sua vez uma personalidade juridica, póde traçar certos limites, certas restricções á sua soberania, sem que por isso perca essa qualidade, que é a fonte de onde dimanam todos os seus direitos, uma vez que taes limitações sejam determinadas exclusivamente pela sua propria vontade.

Nas relações internacionaes, sempre multiplicadas pelos progressos da civilisação, pullulam abundantes exemplos disso, quer encaremos a varias convenções em materia de communicações postaes, telegraphicas, etc., quer consideremos os differentes tratados de paz e de protectorado que muitas vezes são feitos com intuito de evitar graves perigos.

Mesmo nas relações internas, attendendo a melhores vantagens em sua organisação politica, muitos Estados, têm cerceado, até certo ponto, a sua soberania, garantindo, pela propria lei fundamental, alguns direitos ás collectividades publicas inferiores.

Todas essas delimitaçôes, porém, que parecem quebrar a unidade da soberania, em nada alteram a sua substancia, porque, quaesquer que ellas sejam, internas ou externas, hão de sempre ter por base a vontade suprema do Estado. Este tem o dever de obedecel-as, desde que ellas sejam voluntariamente estatuidas, pois, as regras juridicas tambem se applicam ás relações do Estado com as outras personalidades, e determinam sempre o cumprimento das obrigações assumidas. Mas é claro que, antes de estabelecido o vinculo obrigacional, elle tem a plena liberdade de acceital-o ou recusal-o. 
Postos estes principios, e conhecida a natureza juridica da soberania, tanto quanto baste para podermos guiar-nos com segurança no estudo do assumpto acima indicado, passamos agora a resolver definitivamente a questão.

Si é exacto que na confederação de Estados, (Staatenbund), estes conservam a sua inteira soberania, a qual, por isso mesmo, não existe no poder central por elles organisado, como na Allemanha de I 8 I 5 a 1866, na Suissa em differentes épocas até 1848 , e nos Estados Unidos de 1778 a 1787 , da-se justamente o contrario a respeito do Fstado federal, (bundcsstaat), onde só este tendo o poder soberano, ficam os Estados membros privados completamente. delle.

As idéas erroneas que germinaram e vicejam entre nós, sobre a necessidade de uma soberania dividida, ou melhor duplice, em toda organisação federal de Estados, são devidas quasi que exclusivamente, á influencia poderosa de dois estimados auctores, cujas obras são constantemente consultadas pelos leitores brasileiros. Sằo elles: A. de Tocqueville em sua "De la Democratie en Amérique", e J. Dubs em seu «Droit Public de la Confédération Suisse»

Nos Estados Unidos, onde vamos aprender as mais stibstanciosas lições de direito federal, orde o eminente Chief Fustice Marshall foi um dos más' estrenuos defensores dos direitos da União contra a propaganda infatigavel de Jefferson, ainda ha escriptores que, de certo modo, confundem as noções sobre esta materia; deve-se, porém, notar que alguns, dentre os que mais scientificamente cultivam o direito, 
como o abalisado Thomas Cooley, $\left({ }^{8}\right)$ já não fazem côro com os apregoadores da pretensa soberania dos Estàdos.

$\mathrm{Na}$ Allemanha, onde os estudos juridicos se aprofundam sempre de maneira notavel, não puderam medrar as idéas de Seydel, que, como Calhoun na America, sustentava a soberania dos Estados federados, desconhecendo a do Estado federal, e logo a theoria verdadeira foi se extendendo pela maioria dos juristas, cujas opiniões vão sendo já bem acolhidas emFrança.

$\mathrm{Na}$ Republica Argentina, Estrada, em suas lições professadas na Universidade de Buenos Ayres, reconhece que a Constituição attribuiu ás provincias o seu verdadeiro caracter: "ellas são centros organicos estabelecidos para administração e governo geral da Republica; são provincias, não são Estados; são subdivisões de um Estado e não entidades soberanas, nem, por conseguinte, partes contractantes de uma alliança dissoluvel.

No Brasil, onde poucos annos conta de vida a fórma republicana federativa, peli qual as antigas provincias, fascinadas com a somma de liberdades que thes foi concedida, se julgaram com poderes soberanos sobre os seus respectivos territorios, é mister que, pelo menos, os cultores da sciencia juridica não descancem sobre as noções falsas que se vão accumulando, e consagrem alguma attenção á natureza deste assumpto que tanto nos interessá.

O emerito Ruy Barbosa, o jurisconsulto que mais tem escripto, entre nós, sobre questões de direito federal, não se tem deixado embahir pelo poder dos Estados.

(8) Th. Cooley. - General Principles of. Constit. Lau 2." ei. pag. 16 . pag. 67.

$\left(^{9}\right.$ ) Estrada. - Noções de Direito Federal. (Trad. de R. Octavio) 
E, em um de seus luminosos artigos, diz positivamente que, em a nossa organisação politica, "uma das faces sob as quaes se apresenta a perversão do senso constitucional, é a allucinação das provincias, evadidas á centralisação de hontem, substituindo o principio salutar da autonomia federativa, pela funesta illusão da soberania dos Estados. $\left({ }^{10}\right)$

A importancia pratica desta materia é incontestavel, e triste prova disso nos offerece a historia dos Estados Unidos. Basta-nos dizer com Giacomo Grasso, referindo-se ao grande Estado Americano: "Il sovrano è un solo; $e$ il giorno in cui ne fu revocata in dubbio la souranità, la guerra forse più sanguinosa che siast mai combatuta, ne revendicò la volontà suprema. $\left({ }^{11}\right)$

Para demonstrar-se a verdade da theoria por nós acceita, de que em qualquer Estado federal, e com especialidade no Brasil, sómente elle possue a soberania, e de modo algum as collectividades publicas que o compõem, ésufficiente que verifiquemos a frágil posição dos sustentadores da "theoria contraria, quasi sempre em desaccôrdo com as idéas por elles mesmos enunciadas, e attentemos um pouco para as principaes organisações politicas federativas, taes como se nos apresentam na America e na Europa.

A doutrina de Calhoun e Jefferson, defensores do Slates Rights, affirmando que só os Estados conservam a soberania, a despeito de serem partes cons-

${ }^{\left({ }^{10}\right)}$ Ruy Barbosa. - Artigo I sobre Impostos Interestaduaes publ. no Jornal do Commercio.

- O presidente da Republica, dr. Prudente de Moraes, entre os pirincipios que se comprometten a observar no governo, estatuiu em seu manifesto, o seguinte: "Execução fiel do regimen livre e democratico, adoptado pela Constituição de 24 de Fevereiro, firmando e mantendo escrupulosamente a autoromia dos Estados, harmonica com a soberania da União, e a independencia e mutuo respeito dos poderes instituidos como orgams dessa soberania."

(11) G. Grasso. - Costituzione degli St. Uniti (1894) pag. 25. 
titutivas da União federal, é tão flagrantemente antinomica aos principios e á realidade visivel dos factos, quie se acha hoje completamente repudiada por quasi todos os auctores. Baseando-se no principio de que a constituição é um tratado, e não uma lei, estabelecem $\in$ lles que os Estados, achando se vinculados por meio de um pacto, são e permanecem soberanos; o governo federal, sendo uma creação destes, os seus orgams não podem pretender nenhuma auctoridade sobre os Estados, pelo que, não têm direito de annullar acto algum por qualquer delles praticado.

$E$, em consequencia de sua doutrina, deduzem que os Estados particulares podem annullar as leis federaes, quando as julgarem oppostas á constituição, e podem separar-se da União, quando assim o entenderem conveniente, isto é, têm o direito de nullificação e o de secessão-duas armas perigosissimas contra a unidade da organisação politica do Estado federal. A «Confederação dos Estados do Sul» concluida em Montgomery, que perdurou de i86 I a I865, foi um exemplo terrivel dos resultados funestos de tal theoria.

Por outro lado, a doutrina exposta por Tocqueville, repousa no presupposto de que o Estado federal funda-se tambem em um tratado, reconhecendo, entretanto, que este, uma vez executado, se transforma em lei, e que essa lei é a constituição federal. Os Estados, acceitando-a, perdem todo o direito de secessão, e a respeito de tudo quanto elles attribuem ao poder central, as leis federaes são superiores ás suas proprias. Todavia, accrescenta elle, em suas respectivas espheras, excluidos os determinados objectos de competencia federal, os Estados permanecem soberanos, e, por consequencia, não dependem, de modo algum, do poder central. ( $\left.{ }^{12}\right)$

$\left({ }^{12}\right)$ A. de Tocqueville. - De la Democratie en Amerique -17 ed. 
Differentemente de Tocqueville, entende Dubs, referindo-se á constituição federal suissa, que ella tem natureza mixta: é em parte um contracto, quando determina as relações entre as diversas soberanias na confederação, $\left({ }^{13}\right)$ e em parte uma lei, quando regula detalhadamente o organismo do Estado federativo e os direitos e liberdades do povo; dahi conclue elle que "as associações organicas são caracterisadas pelo facto de possuirem todas em si uma dupla soberania. soberania dos Estados particulares e soberania da Confederação. $\left({ }^{14}\right)$

Pelas noções já conheciclas sobre a soberania, facilmente se deprehende que nenhuma dessas theorias se harmonisa com os principios do direito publico.

Das constituições federaes existentes, não ha uma só que, juridicamente, possa ser considerada um tra tado, ou um pacto entre Estados. Sob o ponto de vista historico, é verdade que alguns Estados, desejosos de viver em uma organisação politica mais apro. priada aos seus interesses, têm estabelecido, por meio de um pacto, o projerto de formação de uma personalidade juridica superior, onde se realise a fusĩo de todos elles em um Estado federal. Ahi estão, para exemplo, os Estados Unidos da America, e a Confederação da Allemanha do Norte, feita Imperio da Allemanha em i 870 . Mas, em nenhum desses paizes, as respectivas constituições têm o caracter juridico de um tratado. No momento em que nasce o Estado,

\footnotetext{
${ }^{(13)}$ A Suissa, apezar de ser uın Estado federal, ainda conserva o nome de Confederação Suissa. part (1879).

(14) J. Dubs. - Le Droit Public de la Confédération Suisse, 2."

- Adans et Cunningham reconhecem que os juristas não acharão maito exacto o termo - dupla soberani: , - visto não poder haver "em uın Estadı sinão um só poder suprêmo ou soberano". Pretendem, porém, justifical-o, "por ter sido o seu uso consagrado na Suissa. - La Confédération Suisse (1890) pag. 27.
} 
que é o objecto do pacto anteriormente concordado, este desapparece para dar logar á constituição que, promulgada em nome do Estado federal, surge como uma perfeita lei, a lei fundamental da nova organisação politica, á qual os Estados, não mais soberanos, devem obediencia. Os laços contractuaes que anteriormente existiam, apagam se, desfazem-se, por já haverem produzido o seu effeito, e, a todos os individuos e collectividades que se acham no territorio do Estado, impõe-se a regra superior de direito cuja manutenção, cuja modificação ou abrogação não dependem mais, desde então, sinão da vontade do Estado federal. As relações deste para com os seus membros, não são iguaes áquellas que se originam de um tratado, mas são relações de dominação e de subordinação simplesmente reguladas pelo direito politico interno. ${ }^{(15)}$ )

Estudando a natureza da constituição norte-americana, aquella que, pelas circumstancias que rodearam o seu nascimento, mais 'tem despertado a attenção dos que a. julgam um simples pacto, o sabio Story. $\left({ }^{16}\right)$ refuta vigorosamente os argumentos todos apresentados nesse sentido, e com firmeza, sustenta que, já pela analyse de seu texto, jấ pela sua formação historica, já pelas relações existentes entre o poder federal e seus membros, não se a pode reputar como contendo aquelle caracter

Permitta-se-nos a transcripção do seguinte trecho, que é uma proveitosa lição sobre o assumpto:

"Por um pacto (a compact)", doutrina o notavel escriptor "não queremos dizer um äcto de solemne assentimento do povo a uma forma de governo,

${ }^{\left({ }^{15}\right)}$ re Fur - op. cit.

${ }^{\left({ }^{16}\right)}$ Story - Commentaries on the Const. of the United States 5 th ed. vol. 1 c. III. 
(sobre isso não existe duvida); porém sim, um contracto impondo obrigações mutuas, e suppondo a subsistencia permanente de partes, que têm direito independente para crear, fiscalisar e julgar de suas obrigações. Si um pacto deve ser julgado neste ultimo sentido, deve sel-o, ou porque contem em sua letra clausulas com esse fim, ou porque ahi se acha naturalmente envolvido pela natureza e objecto de um systema de governo.

Não se encontra na letra da Constituição, clausula alguma suggerindo ser ella um pacto, ou permittindo, de qualquer modo, que seja interpretada como tal.

Pelo contrario, emphaticamente o preambulo apresenta-a como uma lẹi solemne, e estabelecimento de um governo. A sua linguagem é: "Nós, o povo dos Estados Unidos decretamos e estabelecemos esta Constituição para os Estados Unidos da America.

$\mathrm{O}$ povo decreta e estabelece, não contracta e estipula entre si. $O$ povo dos Estados Unidos, não o povo distincto de um Estado particular, com o povo dos outros Estados. $\mathrm{O}$ povo decreta e estahelece uma constituição, não uma confederação. A distinç̧ão entre uma constituição e uma confederação é bem conhecida e comprehendida... A primeira é uma forma permanente de governo em que os poderes, uma vez outorgados, são irrevogaveis e não podem ser retomados ou retirados á vontade. Quer formada por um só povo, quer por diversas sociedades de povos em sua capacidade politica, uma constituição, embora nascida de um accôrdo, uma vez ratificada, torna-se obrigatoria como uma lei ou decreto fundamental. As obvias deducções que podem ser tiradas, e que com effeito o tem sido, do facto de considerar-se a constituição como um pacto entre os Estados, são que ella age entre elles como simples tratado ou convenção, que cada Es- 
tado tem direito de julgar por si em relaçấo á natureza, extensão e obrigação do instrumento, sem ser de modo algum limitado pela interpretação do governo federal ou pela lei de um outro Estado. Essas doutrinas vão ao ponto de reduzir o governo a uma mera confederação de Estados em quanto lhes agradar, e apresentam, desse modo, o extraordinario espectaculo de uma nação que existe somente ao arbitrio de cada uma de suas partes constitutivas».

A opulenta jurisprudencia americana tem sempre entendido por essa forma, e a Suprema Côrte assim o decidiu na sentença com que julgou o caso Culloch v. Marylland. "A Convenção que architectou a Constituição", disse ella, "foi com effeito, eleita pelas legislaturas dos Estados:

Porém o instrumento, quando sahiu de suas mãos, era um simples projecto, sem obrigações ou pretensões a isso Foi elle relatado ao Congresso, então existente, dos Estados Unidos, com um pedido para que fôsse submettido a uma convenção de delegados escolhidos, em cada estado, pelo respectivo povo, com a recommendação de suas legislaturas para o assen. timento e ratificação. Adoptado esse modo de proceder, foi o instrumento, pela Convenção, pelo Congresso e pelas legislaturas estaduaes submettido ao povo. E' dessas convenções que a Constituição tira toda a sua auctoridade, e, desde que foi acceita, permaneceu como completa obrigação, e limitou a soberania dos Estados»

A constituição americana é, portanto, como todas as outras que foram o resultado de um accordo entre Estados anteriormente soberanos, cousa muito differente de um tratado ou de um pacto; é umá lei suprêma que estabelecendo a organisação politica do Estado, extende o seu dominio por todo o territorio, 
e opera directamente sobre o povo, quer considerado em seu conjuncto, quer em agrupamentos de Estados federados. Com maioria de razão, pode-se dizer isso mesmo a respeito da constituição brasileira, bem como da do Mexico, que nasceram em virtude da transformação de um Estado unitario em estado federal. Sobre a natureza destas, parece-nos que jámais pairou a menor duvida. As provincias que viviam dominadas sob o peso de apertada centralisação, só puderam gosar das liberdades concedidas, quando formou-se o Estado federal com o estabelecimento de sua constituição. Esta, na qualidade de lei suprêma, é que determina o molde no qual se devem calcar as constituições dos Estados particulares; e os orgams do poder federal, por ella mesma creados, são os fiscalisadores constantes dos actos por aquelles praticados, afim de forçal-os á obediencia devida, no caso de possivel transgressão a qualquer dos preceitos geraes por ella traçados.

Mas, só essa idéa de fiscalisação. no exercicio dos poderes de um governo, ensina Story, encerra virtualmente a negação da supremacia desse governo a respeito de seus poderes, supremacia proclamada, entretanto, pela constituição federal. $\left({ }^{[} 7\right)$

Que importa que algumas constituições, como a da Suissa, artigo $3 .^{\circ}$, declarem, em sua linguagem, as mais das vezes defeituosas, que os Estados, ou Cantões são soberanos?

Pois não são ellas mesmas que, pelas limitações feitas aos poderes dos Estądos, destróem, nihilificam a afamada soberania com que os presenteam, apenas de nome, para satisfazer ou o seu amor pelas tradições, ou a sua vaidade politica?

$\left({ }^{17}\right)$ Story op. cit. 
Por isso, Cooley, comprehendendo que o termo "sovereignty in its full sense, imports the supreme, absolute, and uncontrollable power by which any independent state is governed, chega a confessar que, não obstante terem sido os Estados chamados soberanos na Declaração da Independencia, nunca tiveram estrictamente esse caracter, porque, relativamente a alguns dos mais altos poderes da soberania, estiveram sempre sujeitos á censura de uma auctoridade commum e jamais foram separadamente reconhecidos como membros das familias das nações". $\left({ }^{18}\right)$

A "dupla soberania» que Dubs pretende enxergar na organisação denominada Estado federal, não se compadece nem mesmo com a noção que elle proprio nos ministra do que seja soberania.

Diz elle que a sua essencia consiste no direito de livre determinasãa politica, de maneira que, onde este faltar, não pode existir aquella. $\left({ }^{19}\right)$

Mas,-perguntamos-onde esse direito de livre determinação nos Estados particulares? Quem será capaz de affirmar, perante os textos das constituições, que elles possuem tal direito?

Pois não é exacto que elles não têm o direito de escolher a forma de seu governo, a qual lhes é imposta pelas respectivas constituições federaes? $\left({ }^{20}\right)$

Pois não é certo que não podem elles, quasi todos, concluir certas convenções, quer entre si, quer com potencias extrangeiras, sem que sejam ellas levadas ao conhecimento do poder federal, para appro-

( ${ }^{18}$ ) Cooley - General Princ. cit. pag. 16.

( $\left.{ }^{10}\right)$ Dubs - Op. cit. 2.0 part. pag. 36.

$\left({ }^{20}\right)$ V. Cunst. brasileira art. 6. ${ }^{\circ}$ n. 2, dos Eistados Unidos art. IV sec. IV n. 1, suissa art. $6 .^{\circ}$ b), argentina art. 5, mexicana art. 109. A Allemanha só, faz excepção a esta regrá. 


\section{$-78-$}

val-as ou rejeital-as, si accordes ou não com os preceitos constitucionaes? $\left({ }^{21}\right)$

Pois não é verdade que, em geral, são elles absolutamente prohibidos de fazer convenções de caracter politico? $\left({ }^{22}\right)$

E, particularmente, na Suissa mesmo, os cantões não são obrigados a submetter á approvação do poder federal certas leis importantes, como sobre liberdade de imprensa? não se sujeitam á vigilancia do centro sobre a administração da justiça, execução de leis militares, e até sobre manutenção de estradas e de pontes que interessam á Confederação? $\left({ }^{23}\right)$

Onde está, então, o direito de livre determinação politica invocado por Dubs?

$\mathrm{Na}$ monarchia franceza, havia certas provincias que podiam recusar seu concurso á auctoridade central, quando esta ordenava a arrecadação de um imposto...

$\mathrm{Na}$ Hespanha, algumas provincias tinham o direito de organisar alfandegas especiaes...

As colonias inglezas de self government possuem amplos poderes sobre seus territorios, onde agem com grande liberdade a respeito de seus negocios...

Entretanto, ninguem ainda se lembrou de chamal. as soberanas...

No regimen federal norte-americano, quando um Estado decreta uma lei coniraria aos preceitos constitucionaes, o cidadão lesado no momento em que

$\left({ }^{21}\right)$ V. Const. brasileira art. 65 comb. com o art. 48 n. 16, dos Estados Unidos art. I sec. X n. 3, suissa arts. 7 e 9, argentina art. 107, mexicana art. 110.

$\left.{ }^{(22}\right)$ V. Const. brasileira art. $65 \S 1 .^{\circ}$, suissa artigo $7 .^{\circ}$, argentina art. 108. No Mexico, os Estados não podem concluir tratados ou allianças entre si ou com extrangeiros, salvo o caso de liga para guerra contra los barbaros ( $\mathrm{v}$ art. 111).

$\left({ }^{23}\right)$ V. Const. suissa arts. $20,37,55,110$. 
'ella fôr postá em execução, tem o direito de recorrer ao Supremo Tribunal que póde declaral-a inválida. E' conhecido nos Estados. Unidos o processo intentado pelo chim Ho Ah Kow, que conseguiu da Côrte a condemnação de um carcereiro ao pagamento de perdas e damnos, só por the haver cortado os cabellos na prisão, quando, entretanto, esse funccionario tinha agido em obediencia á ordem emanada da auctoridade de S. Francisco, no Estado da California. $\left({ }^{24}\right)$

No Brazil, o Supremo Tribunal Federal, entre as suas importantes attribuições, tem o poder de julgar innocente e mandar pôr em liberdade um cidadão que tenha sido condemnado como criminoso pelo jury estadual. $\left({ }^{25}\right)$

Não; digamos francamente: os Estados federados não são soberanos; elles têm sempre acima de si, elevado, sobranceiro, o Estado federal fiscalisando os seus actos para que não ultrapassem a linha de competencia que lhes foi assignalada.

A theoria de Proudhon sobre a natureza do Estado federal, não pode ser acceitavel; ella vai de encontro ao direito publico, e cahe deante dos textos das constituições existentes.

Definindo a federação, diz elle que é um contracto synallagmatico e commutativo, para um ou muitos objectos determinados, mas cuja condição essencial é que os contractantes se reservem sempre uma parte de soberania e de acção maior do que a que abandonam, ou, em outros termos, é uma convenção pela qual um ou muitos chefes de familia, uma ou muitas communas, um ou muitos grupos de Es-

(24) Bryce - American Commonwealth 3. ${ }^{\mathrm{a}}$ ed. v. 1 pag. 331.

$\left({ }^{25}\right) \mathrm{V}$ art. 81 da Const. federal. Ha ponco tempo $\circ$ Supremo Tribunal usou desse poder relativamente ao jury do Estado de S. Paulo em processo que aqui tinha ficado gelehre. 
tados se obrigam reciproca e egualmente para um ou muitos objectos particulares, cujo encargo é attribuido especial e exclusivamente aos delegados da federação. $\left({ }^{26}\right)$

Mas, eis ahi uma definição que não encerra os requisitos da logica. $O$ seu defeito fundamental, que a destroe completamente, é não estabelecer a differença especifica do objecto que pretende definir. Essa convenção, ou esse contracto feito entre Estados, sem perderem a sua soberania, dando incumbencia a seus delegados relativamente a certos "objectos particulares", é cousa que pode abranger variadissimas especies de associações politicas. Das palavras contidas na definição indicada, não nos é dado concluir que se trata de dizer o que seja um Estado federal.

Das idéas expostas por Proudhon na citada obra, percebe-se que elle confunde inteiramente um Estado federal com uma confederação de Estados.

Assim é que não hesita em affirmar que uma confederação $\left({ }^{27}\right)$ (refere-se ao Estado federal suisso) não é precisamente um Estado, mas um grupo de Estados soberanos e independentes, que aquillo que se chama auctoridade federal, não é um governo, mas uma agencia creada pelos Estados para a execução commum de certos serviços, etc. Dahi deduz elle que a separação de uma minoria dos Estados é de pleno direito, desde que se trate de uma questão de soberania cantonal, deixada fóra do pacto federal. $\left({ }^{28}\right)$

Vê-se pois, que esse auctor, reduzindo a quasi nada o poder federal, e tirando mesmo á federaçâo

$\left({ }^{28}\right)$ Proudhon - Du Principe Fédératif (1868)-- pag. 46 e 52.

${ }^{\left({ }^{27}\right)}$ "Confédération" - Alguns escriptores francezes, e entre elles Proudhon, empregam muitas vezes indistinctamente os termos-fédération e confédération.

$\left({ }^{28}\right)$ Proudhon op. cit. pag. 49-50 not. 
o nome de Estado, torna-a fragil, facilmente quebrantavel em sua unidade, de modo a não poder mais ser considerada como o melhor regimen politico de um povo civilisado. Admittir as idéas de Proudhon é negar a importancia, o valor, a propria vida do Estado federal.

Tocqueville mesmo não se pôde esquivar ao reconhecimento de que nada vale a pretensa soberania dos Estados, $\dot{e}$, forçado pela imposição dos factos que se realisam na America do Norte, escreveu: - Mas todos estes Estados que eu tenho encarado como independentes, são obrigados, entretanto, a obedecer, em certos casos, a uma auctoridade superior que é a da União» $\left({ }^{29}\right)$

E' só esse poder federal que pode praticar verdadeiros actos de soberania, aos quaes todos os cidadãos e Estados particulares devem obediencia, respeitando a lei constitucional.

"Al di sopra di tutti indistintamente $i$ vari gruppi d'individui costituentr lo Stato federale» diz com razão Eduardo Cimbali, "vi è un potere, vi è un governo che li considera tutit come un sol popolo, come un solo Stato, non soltanto nei rapporti internazionali, cioè nei rapporti cogli Stati stranieri, ma anche nei loro rapporti interni, cioè nei rapporti tra Stato e Stato dello Stato federales. $\left.{ }^{30}\right)$

E' dessa alta posição em que se acha collocado, que elle exerce livremente o direito de determinar a sua competencia, -o criterio seguro pelo qual se manifesta a soberania dentro de um territorio. Em virtude dessa faculdade, o circulo de suas attribuiçôes

\footnotetext{
$\left({ }^{20}\right)$ Tocquevilie op. cit. p^g. 193. pag. 183 .

$\left({ }^{30}\right)$ Ed. Cimbali -- Lo Stato secondo il Diritto internazionale
} 
pode ser restringido ou ampliado conforme a sua vontade, embora para esse fim lhe seja indispensavel reformar a constituição.

Temos ouvido dizer que a reforma constitucional é um acto de natureza toda particular; que só se realisa quando o povo, ou o conjuncto dos Estados, resolve por meio de um congresso especial, modificar por accôrdo commum, as instituiçōes que o regem, suspendendo, nesse momento, o governo existente. .

Entretanto, basta um conhecirnento superficial das constituições federaes que existem, para perceber-se logo que si as revisões constitucionaes nã̃o se effectuam repetidamente, e requerem alguma lentidão no seu processo, em vista das difficuldades de que se as rodeiam, para garantia de uma certa estabilidade que devem ter as leis fundamentaes, todavia, não nos parece que possam encerrar qualquer caracter de anormal excepcionalidade. Ao contrario, todas" as consti-

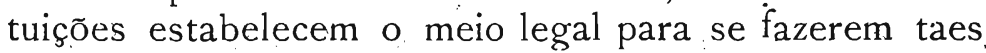
reformas, sem que se dê a menor perturbação na ordem juridica do Estado, e todas ellas attribuem esse direito á União federal, ou, como nos Estados Unidos e na Republica Argentina a orgams especiaes que agem em nome dessa mesma união. ( $\left.{ }^{31}\right)$

$\mathrm{O}$ facto de os Estados particulares tomarem parte directa na revisão, quer pelo direito de iniciativa, quer pelo de approvação das emendas, em nada altera a substancia da soberania do Estado federal, pois elles, assim procedendo, o fazem fundados unicamente nos artigos da constituição deste, e, por consequencia, na vontade do proprio Estado federal. $\left({ }^{32}\right)$

$\left({ }^{31}\right)$ V. Const. brasileira art. 90 , dos E. Unidos art. 5 , suissa arts. 119,120 e 121 , allemã art. 78, mexicana art. 127, argentina 30.

$\left({ }^{32}\right)$ Le Fur op. cit. 
Demais, esses direitos que lhes são assim garantidos, constituem o meio directo pelo qual, além da sua representação no senado, elles, como orgams da federação, participam da propria substancia da soberania do Estado Federal. E' esse um dos traços essenciaes, inherentes a essa fórma de Estados, e que principalmente a distinguem do Estado unitario.

O Estado federal pode, por consequencia, pela maneira exposta, determinar livremente a sua competencia, ao passo que um só Estado particular não tem a faculdade nem de extender a orbita de attribuições que lhe foi demarcada, nem de evitar que o poder central dê maior amplitude á esphera de seus proprios direitos. ${ }^{33}$ )

Além disso, em virtude do importantissimo papel que desempenha o Supremo Tribunal, em certos Estados, no julgamento dos conflictos que entre elles se levantam, incumbe-lhe, por sua vez, determinar as competencias, resolvendo as duvidas que lhe são apresentadas.

A respeito da Suprema Côrte, diz Tocqueville, que ella foi investida do direito de decidir todas as questões de competencia. E, então, receioso pela sorte da soberania dos Estados que elle tanto defendêra, exclama contricto: "esse foi o golpe mais perigoso vibrado contra a soberania dos Estados. Ella se achou assim restringida, não sómenté pelas leis, mas ainda pela interpretação das leis; por um limite conhecido, e por outro desconhecido; por uma regra fixa, e por uma regra arbitraria.

$\left({ }^{33}\right)$ Algumas constituiçǒes garantem certos direitos aos Estados, mesmo no caso de revisão; mas esses direitos garantidos se baseam na propria lei federal, e representam, por ssso, restricções feitas voluntariamente pelo Estado federal á sua propria soberania. A possibilidade destas restriç̧ões já ficou acima explicada. 
A constituição tinha, na verdade, posto limites precisos á soberania federal; mas cada vez que esta soberania se achar em concurrencia com a dos Estados, é sempre um tribunal federal que deve pronunciar a decisão». $\left({ }^{34}\right)$

Mais uma vez, pois, manifesta-se, nitidamente a verdade que sustentamos, isto é, que a soberania só pertence ao Estado federal.

Determinada a natureza das collectividades publicas componentes do Estado federal, bem como a posição juridica que occupam em frente deste, comprehende-se agora, sem necessidade de desfigurar as noções technicas do direito, como se faz a partilha das attribuições conferidas aos Estados federados, e como se harmonisam perfeitamente com os principios juridicos aquellas limitações com que o Estado federal thes cercêa os poderes, e que constituem para com elle em bem da unidade essencial ao todo organico, deveres ineluctaveis cujo cumprimento impõe-se pela força das necessidades.

Fôra baldada tarefa procurar-se uma base invariavel sobre a qual deva assentar a distribuição das competencias entre o poder central e os Estados particulares.

Differentes no espaço e no tempo as condições em que vivem os povos, graças ao seu diverso gráo de desenvolvimento cultural, não encerram todos os agrupamentos que se tornam orgams formadores de Estados, capacidade egual para regerem os negocios que mais de perto lhes interessam.

De mais, tendo em consideração as experiencias já feitas por aquelles Estados que de ha muito vivem

$\left({ }^{34}\right)$ A. Tocqueville op. cit. pag. 248. 
sob o regimen federativo, é natural que os outros, ao estabelecerem os delineamentos de sua construcção politica, vão desde logo fazendo as modificações que se mostrarem vantajosas. Por isso é que, emquanto nos Estados-Unidos, os Estados particulares gosam de importantes direitos, tão vastos que têm por vezes produzido serias difficuldades aos poderes federaes, como por exemplo, no celebre incidente italo-americano da Nova Orléans, - na Suissa, a tendencia geral é para ampliação da competencia federal, e no Brasil como no Mexico, em virtude de sua origem unitaria, as attribuições estaduaes são consideravelmente limitadąs. Relativamente ao poder de legislar sobre o direito substantivo, que no primeiro desses paizes, foi deixado aos Estados, observa-se um movimento extensivo da competencia da Uniâo nos outros que appareceram depois, onde as vantagens incontestaveis da unificação do direito vão se impondo de modo notavel. Assim, na Republica Argentina, lá está o artigo 67 n. I I da constituição, na Allemanha o artigo $4 .^{\circ}$, na Suissa os artigos 64 e outros, no Mexico art. 72, no Brasil art. 34 n. 23. Si em uns, se camiruha a largos passos para a unidade legislativa, onde já se apontam monumentos como o codigo civil allemão e o codigo federal suisso das obrigações, em outros, como no Brasil, se acha francamente estabelecido o systema de um só direito nacional.

Do modo vario pelo qual as constituições federaes, attendendo a circumstancias complexas dos respectivos paizes, a motivos de pura tradição historica, têm feito a distribuição das competencias, conclue-se que não é possivel indicar seguramente quaes as que devem pertencer exclusivamente ao Estado federal, e quaes as que possam ser concedidas aos Estados particulares. Só o que nos é permittido fazer, para não nos enredarmos em difficuldades invenciveis, é 
dizer, em termos geraes, que, na discriminação das attribuições, deve-se attender ao criterio da necessaria integridade para a conservação, vida e independencia do Estado, reservando á União todos os poderes de interesse geral, que se mostrarem indispensaveis para que ella não perca a sua soberania nas relações internas e externas.

A maioria das constituições, na impossibilidade de taxar explicitamente cada um dos direitos conferidos aos Estados, declara que, além dos principaes que se acham estatuidos, elles conservam todos aquelles que não tiverem sido attribuidos ao poder central, ou que não lhes tenha sido negado expressamente. $\left({ }^{35}\right)$

Em compensação, para evitar os abusos que dahi poderiam resultar, e para cercar de garantias o funccionamento dos orgams federaes, encerram ellas sem. pre uma clausula pela qual deixam á União o direito de decretar as leis necessarias ou convenientes ao exercicio dos poderes que lhe competem. $\left({ }^{36}\right)$

E' essa a clausula denominada pelos norte-americanos - a clausula elastica - a respeito de cuja interpretação profundas questões se levantaram, dividindo-os em dois grandes partidos politicos.

Assim, indicado, em largos traços, o systema que deve ser seguido para a distribuição das competencias, em um regimen federativo, julgamos não ser necessario fazer a analyse das attribuições reservadas pelas diversas constituições ao poder federal, taes como as de legislar sobre moedas, pesos e medidas,

$\left({ }^{35}\right)$ V. Const. brasileira art. $65, \S 20^{\circ}$ dos Est. Unidos emenda X, suissa art. $3 .^{\circ}$, argentina art. 104 , mexicana art. 117

$\left.{ }^{(39}\right)$ V. const. brasileira art. 34 n. 33 , dus Eistados Unidos art. 1.' sec. 8 n. 18, argentina art. 67 n. 23, mexicana art. 72. A const. suissa, no art. $3 .^{\circ}$ dispondo sobre o fim da Confederação, concede a esta immensos poderes. A respeito, diz Dubs, que desse artigo se servem por vezes "para fazer um pouco de cintrabando". 
naturalisação, etc., não só porque um estudo desses nos levaria a alongar demasiado este modesto trabalho, como ainda porque, afastando-nos da rota clelineada, desviar-nos-á do objectivo a que nos propuzemos.

Ao lado dos direitos que lhes são concedidos, têm os Estados certos deveres que lhes são impostos, cujos principaes, como uma consequencia da falta de soberania, tambem constituem, segundo Le Fur, (37) differenças visiveis entre o Estado federal e a confederação de Estados.

Taes deveres, que são os mais importantes pelos effeitos que delles decorrem, se referem ás limitações seguintes: a) os Estados não podem, por sua propria auctoridade, annullar uma lei federal, b) não podem. em caso algum separar-se da União, c) não podem resolver os conflictos havidos quer entre si, quer com o Estado federal, d) não podem se oppôr ás decisões do poder federal que tem o direitc de, si tanto for preciso, fazel-as executar por meio da força.

- Com effeito, o direito de nullificafãa,-que é aquelle pelo qual um Estado confederado julga em ultima instancia os conflictos de competencia levantados com o poder central,---desapparece inteiramente desde que se trate de um membro do Estado federal. Neste caso, o geral principio regulador é a predominancia da lei federal sobre a estadual. (38)- Bundesrecht bricht Landesrecht-dizem os allemães em phrase. concisa. Por isso, sempre que um tribunal de Estado particular pronunciar decisão contraria á validade ou applicação de lei federal, é permittido recurso para a auctoridade central que dirá a ultima palavra sobre

$\left({ }^{37}\right)$ Le Fur op. cit.

$\left.{ }^{38}\right) \quad$ V. Const. brasileira art. $59 \S 10^{\circ}$, dos Estados Unidos art. VI n. 2, allemã art. $2 .^{\circ}$, suissa art. 113 e 2 das disp. trans., argentina 31 mexicana 126. 
a questão. "A eșcala é quadrupula", diz Ruy Barbosa, traduzindo elegantemente a lição do Bryce "a constituição federal, as leis feủeraes, as constituições de Estados, as leis destes. A successão em que acabo de enumeral-as, exprime-lhes a jerarchia legal.

Dado o antagonismo entre a primeira e qualquer das outras, entre a segunda e as duas subsequentes, ou entre a terceira e a quarta, a anterioridade na gradação indica a precedencia na auctoridade. Uma vez manifesta a collisão, está ipso facto resolvida. A lei mais fraca cede á superioridade da mais forte." ( $\left.{ }^{39}\right)$

A solução por essa forma é a unica possivel; si assim não fosse, ficaria offendida a soberania da União, que seria posta na contingencia de não poder executar as suas leis, uma vez que não se puzesse de accordo com a boa vontade dos Estados $\left({ }^{40}\right)$

-Do mesmo modo, o direito de secessão-que é aquelle pelo qual o Estado confederado pode separar-se da Confederação, quando julgar attentatorio de sua soberania qualquer acto por ella praticadonão compete a um membro do Estado f€deral que é obrigado em todo caso a guardar a posição em que o collocou a constituição federal.

- No State has a right to declare an act of the federal government invalid. No State has a righr to secede from the Union. The only authority comptent to decide finally on the constitutionality of an act of Congress, or of the national executive, is the federal judiciary.

$\left({ }^{39}\right)$ Ruy Barbosa - Act. Inconstitucionaes.

- Kent's - Commentaries (1892) vol. 1 pag. 314.

$\left({ }^{40}\right)$ Parece-nos, portanto, incorrecta a phrase de Boutmy quando diz que as constituições dos Estados são a base do editicio de que a federal é unicamente a corôa. - Dir. Constitucional (trad. de L. Mendonça) pag. 109. 
Foram estes os principios que, segundo Bryce, (41) ficaram estabelecidos desde a guerra civil de I 86 I a 1865.

Eram, pois, juridicamente verdadeiras as celebres palavras de Lincoln, na mensagem de 4 de Julho de I 86I: Os Estados têm o seu status na União, e não têm outro status legal.»

A indestructibilidade da União garantida constitucionalmente, não pode ser atacada pela acção de um Estado, e, quando este, por acto violento, pretender fraccional-a, perde o caracter legal de Estado, dá-se uma perfeita revolta, e ao conjuncto dos individuos rebeldes, o poder federal, uma rez vencedor, pode punir conforme a gravidade da offensa. A pena infligida aos "Estados do Sul da America», é um exemplo imperecivel na historia, e com esse tremendo desastre politico, tombou combalida, por um golpe profundo, a exagerada doutrina dos States Rights.

- Ainda para segurança da estructura politica do Estado, cumpre aos seus membros, dado o caso de conflicto entre si, ou com o poder central, submetter-se á decisão proferida definitivamente por uma auctoridade federal. Todas as constituições o têm assim estatuido expressamente, attribuindo essa importantissima funç̧ão ao supremo tribunal federal, salvo, quanto a este ponto, a Allemanha, onde tal competencia é dada ao Bundesrat, quando as questões não versem sobre direito privado. Com esse grande poder, encarregado de harmonisar pela interpretação do direito, as collectividades inferiores, obrigando-as a permanecer na esphera demarcada de sua competencia, fica prohibido o uso da força entre os litigantes, privados, por consequencia, do direito de

(41) Bryce - The American Commonwealth 3." ed. v. 1 p:'g. 337 
guerra. Algumas constituições, e entre ellas a brasileira, além do systema indicado para solução dos pleitos interestaduaes, ainda contêm disposições especiaes impondo aos Estados a prohibição do uso das armas. ( $\left.{ }^{42}\right)$

"O poder de decidir as causas entre dois Estados» diz Hamilton, (43) «é essenciál á paz da União. O horrivel quadro das dissensões e das guerras civis que dilaceraram o imperio germanico, mostra qual foi o poder desta instituição para fazer cessar as desordens e dar a paz ao imperio».

A posição elevada de uma auctoridade judiciaria mantendo a paz entre os Estados, é uma das mais extraordinarias invenções que tem havido em instituições governamentaes.

Por esse meio, as ardentes questões que, entre milhares de individuos, inflammam as paixões politicas, vão morrer calmamente no recinto sereno de um tribunal de justiça. Tocqueville como que deslumbrado pelo valor e importancia da Suprema Côrte norte americana, escreveu esta significativa apreciação: Quando o porteiro, adeantando-se para os degraus do Tribunal, pronuncia estas poucas palavras:-O Estado de New-York contra o de Ohio»,-sente-se que não se está no recinto de uma côrte ordinaria!» (44)

- Mas que importancia teriam, para garantia da ordem social e politica, essas grandes faculdades do art. 109 .

${ }^{\left({ }^{2}\right)} \mathrm{V}$. Const. brasileira art. 66 n. 3 , suissa art. 14, argentina

$\left({ }^{43}\right)$ O Federalista (trad. portngueza) 3. ${ }^{\circ}$ vol. pag. 172.

${ }^{(44)}$ Tocqueville - op. cit.

- Ainda, ha pouco, o nosso Supremo Tribunal federal rejeitava uma excepção de incompetencia, tendo diante de si, como partes litigantes, o Estado de Amazonas e o Matto Grosso. V sentença de 23 de Junho da 1892 . 
poder federal, sinão possuisse elle os meios necessarios para fazel-as respeitar por todos os Estados?

Eis porque a estes incumbe o dever de prestar obediencia ás decisões emanadas da União. Expresso em algumas constituições, ( $\left.{ }^{45}\right)$ o direito de recorrer á "execução federal, (Bundesexekution), no caso de necessidade, é uma consequencia que fatalmente decorre da soberania.

O Estado Federal, na sua proeminencia, debruça-se sobre todos os membros que o compõem, bem como directamente sobre os individuos que se congregam em seu seio; e, ao lado da acção protectora da harmonia nacional, devem existir os meios coercitivos indispensaveis para que, no exercicio das funç̧ões de suas auctoridades, não sejam estas embaraçadas por obstaculos de qualquer ordem, e possa tornar-se efficaz a supremacia das leis nascidas sob o imperio da constituição federal.

Dahi, essa ramińcação de representantes do poder central que, extendendo-se pelas diversas circumscripções particulares são encarregados de fazer effectivas as ordens federaes.

Entre essas limitações, as mais importantes para conservar-se inalteravel a estructura do corpo politico, outras muitas existem, tendentes todas a garantir a estabilidade da ordem social, e a facilitar o desenvolvimento progressivo do Estado.

Deixamos, porém de analysal-as, porque não o exige a natureza do estudo que aqui viemos. esboçando.

Com as idéas expostas, que nos parecem ser as verdadeiras, sob o ponto de vista puramente juridico art. 19 .

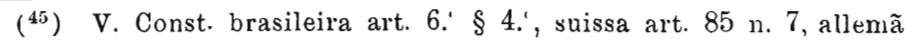


em que nos collocamos, não se deduza que sejamos infenso ao poder dos Estados. Ao contrario: queremol-os grandes e opulentos, e, por isso, é que desejamos vel-os em inquebrantavel harmonia, sob a força avigorante da União.

"Quando o povo americano", disse Carlier, "quiz ser dignamente representado no exterior e organisar fortemente no interior interesses de uma ordem elevada, creou um poder novo, cujas prerogativas sabiamente determinadas, foram um desmantelamento parcial da soberania dos Estados. ( $\left.{ }^{46}\right)$

Só assim se realisará, debaixo das formas com plexas do regimen federativo, $\Theta$ notavel phenomeno politico da maior liberdade possivel dos Estados federados, ante, a unidade excelsa da soberania que constitue a grandeza de um Estado Federal.

Este trabalho está imperfeito; sabemol-o. Necessidades de outra ordem obrigaram-nos a não dar-lhe o desenvolvimento correspondente as exigencias do assumpto.

A douta Congregação solicitamos excusas pela nossa incompetencia.

São Paulo, 25 de Agosto de 1897.

Reynaldo Porchat.

$\left({ }^{46}\right)$ Carlier:-La Republique Americaine (1890) T. $3 .^{\circ}$ pag. 120. 